\title{
Second Line of Defense Help Desk: Electronic Maintenance Reports \\ Local Maintenance Provider User Guide Rev. 1
}

\author{
RJ Leigh
}

December 2011

\section{Pacific Northwest}

NATIONAL LABORATORY

Proudly Operated by Battelle Since 1965 


\title{
DISCLAIMER
}

This report was prepared as an account of work sponsored by an agency of the United States Government. Neither the United States Government nor any agency thereof, nor Battelle Memorial Institute, nor any of their employees, makes any warranty, express or implied, or assumes any legal liability or responsibility for the accuracy, completeness, or usefulness of any information, apparatus, product, or process disclosed, or represents that its use would not infringe privately owned rights. Reference herein to any specific commercial product, process, or service by trade name, trademark, manufacturer, or otherwise does not necessarily constitute or imply its endorsement, recommendation, or favoring by the United States Government or any agency thereof, or Battelle Memorial Institute. The views and opinions of authors expressed herein do not necessarily state or reflect those of the United States Government or any agency thereof.

\author{
PACIFIC NORTHWEST NATIONAL LABORATORY \\ operated by \\ BATTELLE \\ for the \\ UNITED STATES DEPARTMENT OF ENERGY \\ under Contract DE-AC05-76RL01830 \\ Printed in the United States of America \\ Available to DOE and DOE contractors from the \\ Office of Scientific and Technical Information, \\ P.O. Box 62, Oak Ridge, TN 37831-0062; \\ ph: (865) 576-8401 \\ fax: (865) 576-5728 \\ email: reports $@$ adonis.osti.gov \\ Available to the public from the National Technical Information Service \\ 5301 Shawnee Rd., Alexandria, VA 22312 \\ ph: (800) 553-NTIS (6847) \\ email: orders $a$ ntis.gov <http://www.ntis.gov/about/form.aspx> \\ Online ordering: http://www.ntis.gov
}

This document was printed on recycled paper. 


\section{Second Line of Defense Help Desk: Electronic Maintenance Reports Local Maintenance Provider User Guide Rev.1}

RJ Leigh

December 2011

Prepared for the U.S. Department of Energy

under Contract DE-AC05-76RL01830

Pacific Northwest National Laboratory

Richland, Washington 99352 
PNNL-20420 Rev.1 


\section{Contents}

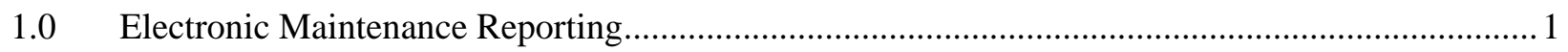

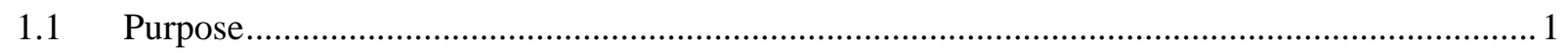

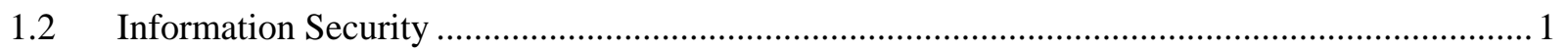

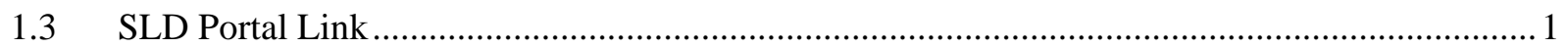

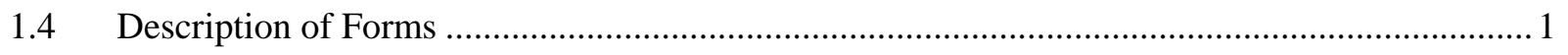

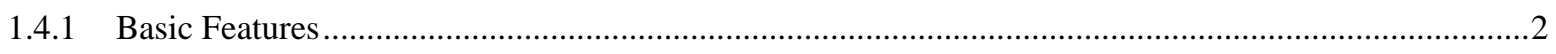

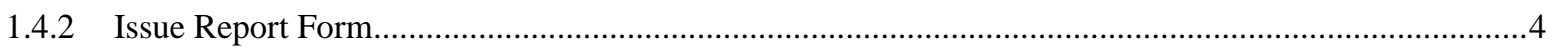

1.4.3 Monthly Maintenance Report …......................................................................................................

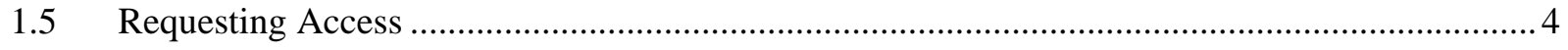

1.6 Sustainability Manager Review of Reports............................................................................. 5

1.6.1 Sustainability Manager “Certifies” a Report as Complete...........................................................................5

1.6.2 Sustainability Manager Requests Additional Information ........................................................................

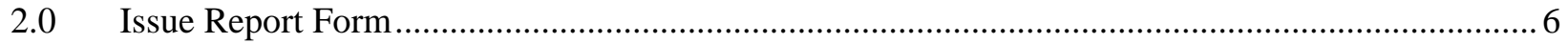

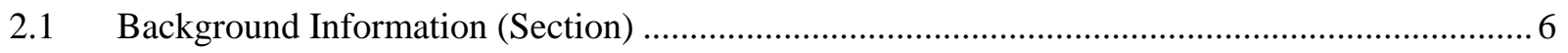

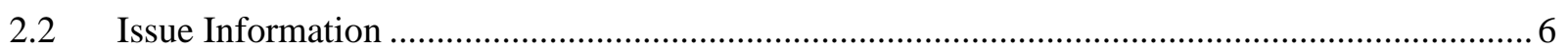

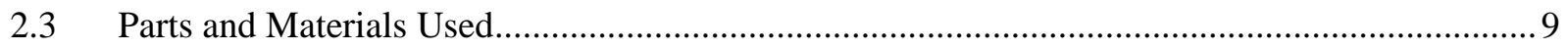

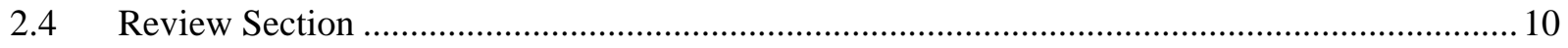

2.4.1 Printing/Saving a copy of the report prior to Completion........................................................................11

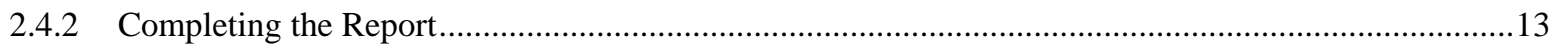

2.5 Sustainability Manager Content Review.................................................................................. 13

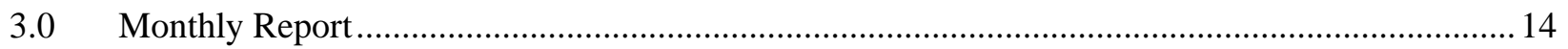

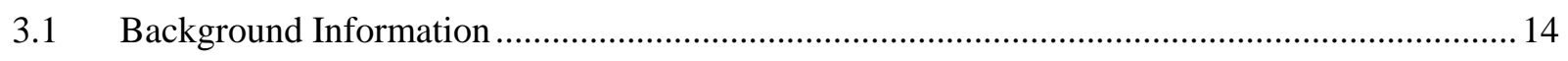

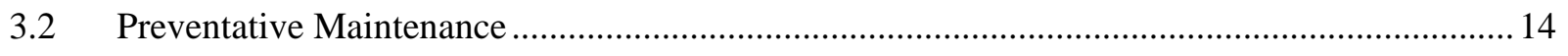

3.3 Related Issues \& Comments .................................................................................................. 17

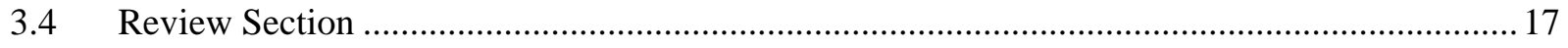

3.4.1 Printing/Saving a copy of the report prior to Completion.......................................................................18

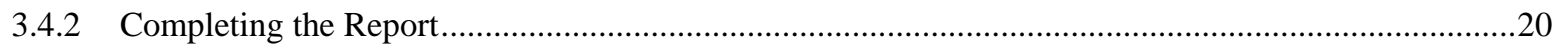

3.5 Sustainability Manager Content Review................................................................................. 20

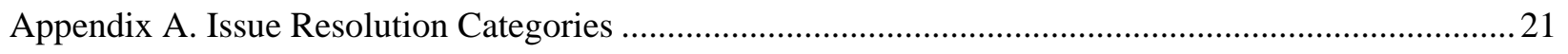

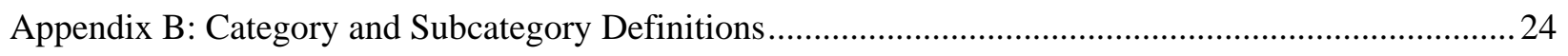




\section{Figures}

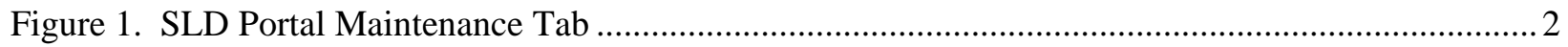

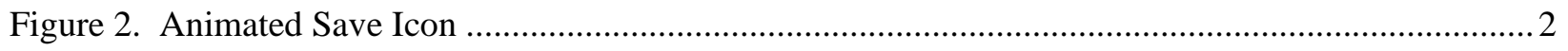

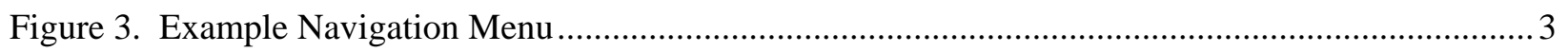

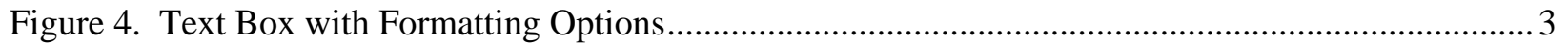

Figure 5. Optional File Attachments Field....................................................................................... 4

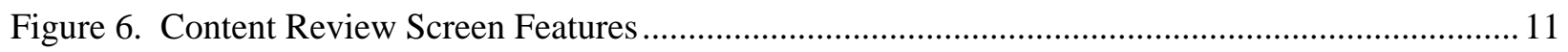

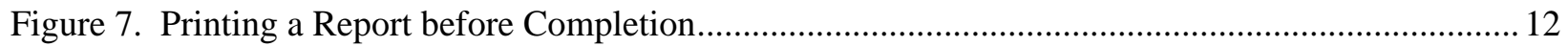

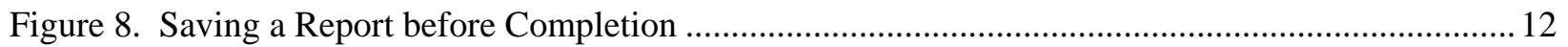

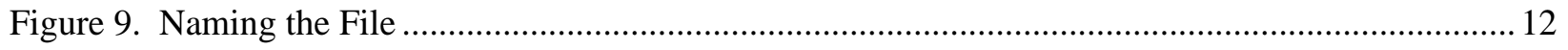

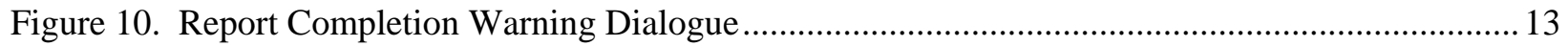

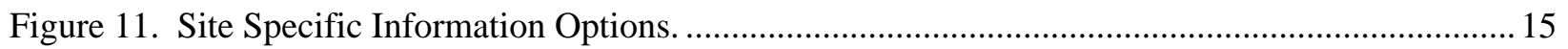

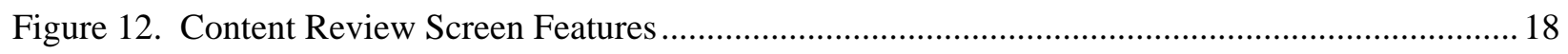

Figure 13. Printing a Report before Completion.................................................................................. 19

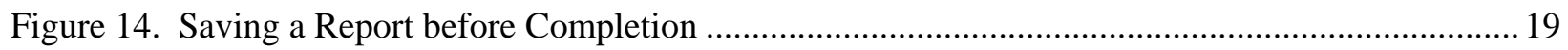

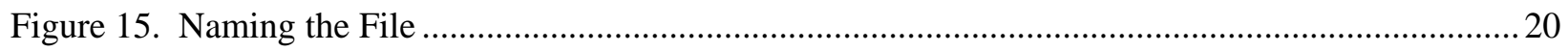

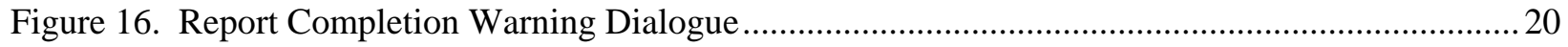




\subsection{Electronic Maintenance Reporting}

\subsection{Purpose}

The Electronic Maintenance Report forms present a uniform dataset for analysis of Sustainability metrics. These forms collect readily minable data while allowing the attachment of site-specific checklists or other supporting files for review by the Sustainability Manager and Program Management.

\subsection{Information Security}

Per the Second Line of Defense Program’s Program Notice 026: SLD Guidance for Contractors on Information Protection Revision 1.0, Maintenance Report information which may contain details of potential system vulnerabilities must be protected as Official Use Only. The Electronic Maintenance Report Forms are contained on the secured SLD Portal website and comply with the criteria established for Official Use Only data. Only authorized users may login and complete the Electronic Report Forms. Users may only view their own "In-Progress" reports. Once a report is marked "Complete" it is only visible to those with an established need to know.

\subsection{SLD Portal Link}

Local Maintenance Providers access the Electronic Maintenance Reports via the externally-facing SLD Portal:

$$
\text { https://sldportal.pnl.gov/index/login }
$$

\subsection{Description of Forms}

The Electronic Maintenance Report forms can be accessed via the Maintenance tab located in the SLD Portal. The Maintenance tab allows the user to create new reports and displays lists of in-progress reports. Once a Local Maintenance Provider has completed a report, the report will no longer appear in the list. 


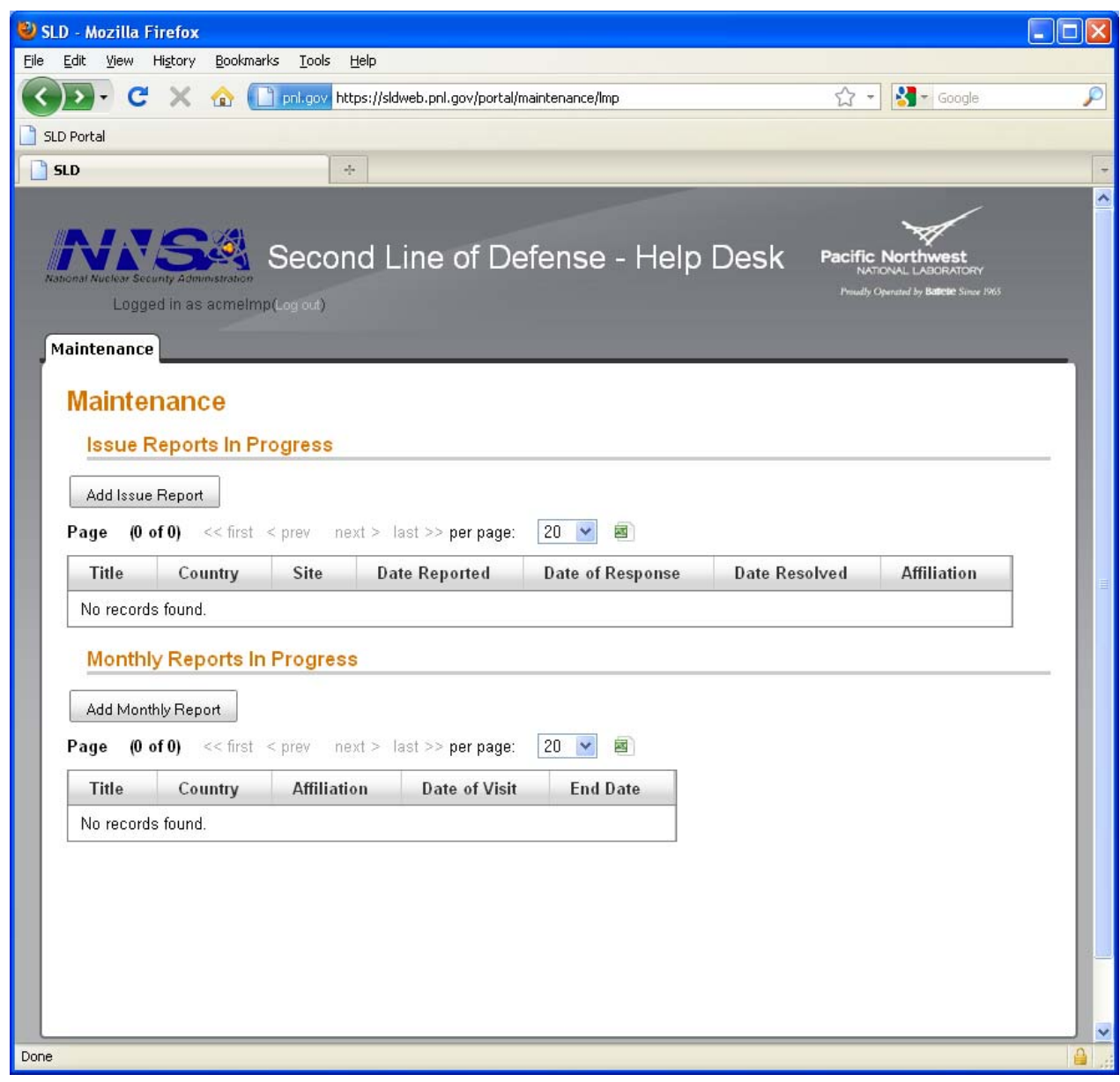

Figure 1. SLD Portal Maintenance Tab

\subsubsection{Basic Features}

The Electronic Maintenance Reports include a number of features which are described in the following sub-sections.

\subsubsection{Data Saved Automatically}

The report is saved as the user moves from one field to another within the form. Saving the form as each field is changed ensures that the data is not lost if the browser window is inadvertently closed or internet connectivity is lost. This save action is represented by an animated circle icon which is shown below for reference.

Figure 2. Animated Save Icon 


\subsubsection{Navigation}

The Maintenance Report Forms are divided into sections, which are listed in a navigation menu on the left side of the report form. Clicking on a Section listed in the navigation menu will take the user to the corresponding report form section. Additionally, the bottom of each report form includes "Previous" and "Next "buttons. Since changes are saved at the field-level as they are completed, the user can move forward and backward in the report without losing data.

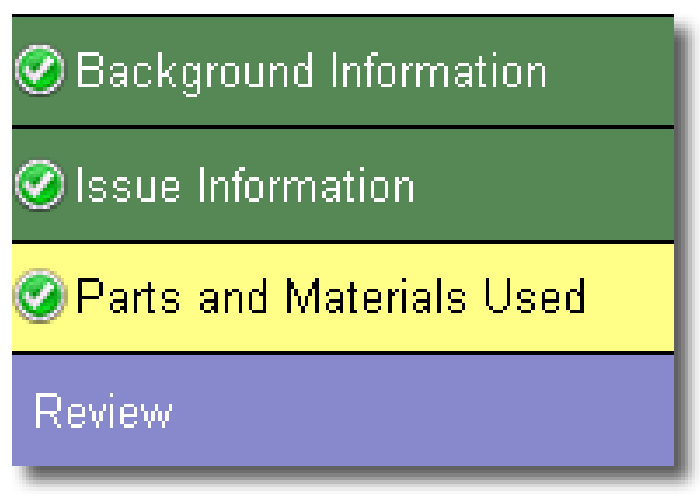

Figure 3. Example Navigation Menu

\subsubsection{Text Formatting Options}

Text fields where longer free-form content may be expected have advanced formatting options. These options are presented in the tool bar at the top of these boxes and allow the user to format their text much like they would when using a word processing program (Bold, Italics, Underline, bulleted/numbered lists, etc.). Advanced copy/paste options allow users to paste text formatted in applications like Microsoft ${ }^{\mathrm{TM}}$ Word while preserving much of its original formatting.

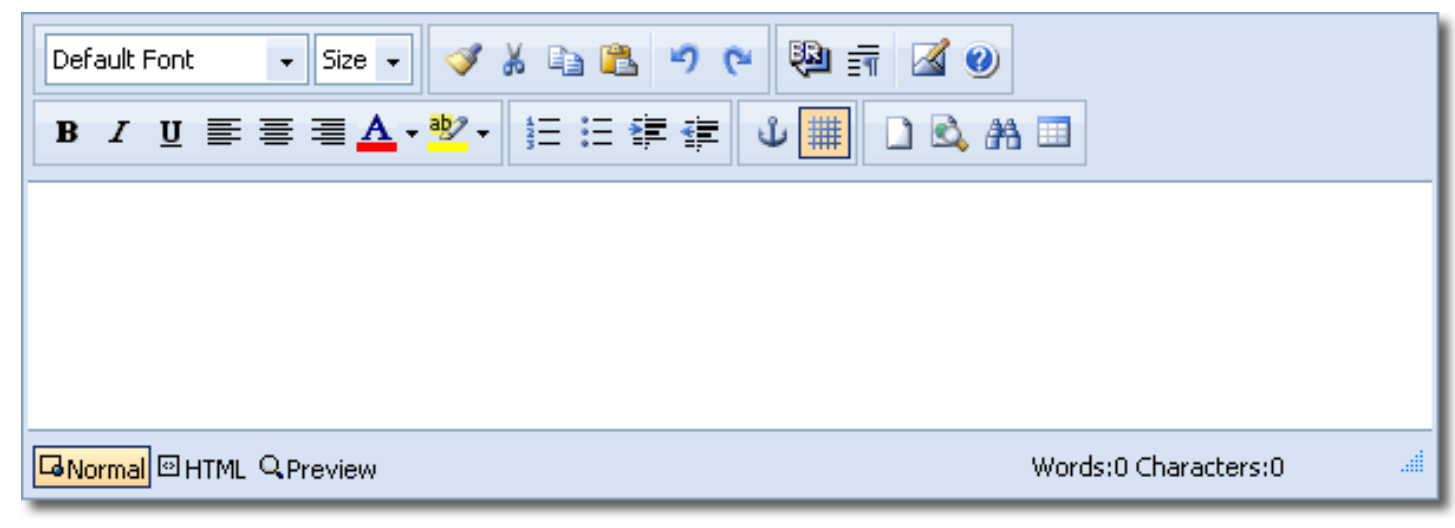

Figure 4. Text Box with Formatting Options 


\subsubsection{File Attachments}

Important: Attached files cannot be used in place of completing fields in the report forms.

Important: File attachments in the Electronic Maintenance Reports do not fulfill the Local Maintenance Provider requirement to upload “daily files” or other archiving. Local Maintenance Providers must continue to submit these files as required by their contract via the ORNL secure upload site.

In order to accurately document issue details or all maintenance work performed, the Local Maintenance Provider may need to attach pictures, scanned copies of checklists, or other supporting documentation. Multiple files can be added and attached to the report form. Additionally, attached files can be removed from the form prior to completion of the report.

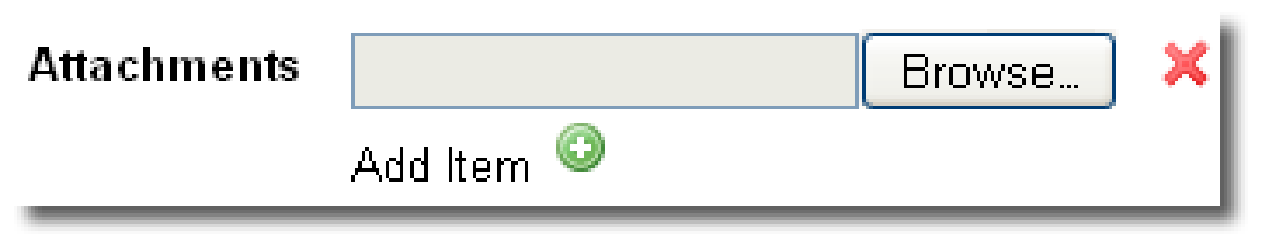

Figure 5. Optional File Attachments Field

\subsubsection{Issue Report Form}

The Issue Report form is intended to capture Corrective Maintenance activities that return equipment to its original operational state. This might include troubleshooting/replacing parts that have failed degrading/disabling a system, realigning optical vehicle presence sensors, etc. Any issues that are reported to the Local Maintenance Provider by a site/Partner Country organization that require an action to return a piece of equipment to an operational state should be documented in an Issue Report.

Each issue should be documented separately in order to support the capture of accurate system reliability data. For example, a failed component in an RPM and a failed hard drive in a CAS Server should be reported on two separate Issue Reports.

\subsubsection{Monthly Maintenance Report}

The Monthly Maintenance Report is intended to capture preventative maintenance data from regularly scheduled Local Maintenance Provider visits to sites; recognizing that these visits may not be conducted monthly for all sites/countries. All preventative maintenance activities/checklists should be included in the Monthly Maintenance Report.

\subsection{Requesting Access}

To request access to the Electronic Maintenance Report Forms, submit a Service Request to the SLD Help Desk (SLDHelpDesk@pnnl.gov). An SLD Portal Administrator will verify the need for access with the corresponding Sustainability Manager/Program Management. The following information will be required to grant access: 
- Name of the LMP organization

- Contract Number with the LMP

- SLD program Point of Contact that engages with the LMP (typically Sustainability Manager)

- Primary LMP Point of Contact

- $\quad$ Phone number of the LMP primary Point of Contact

- Email for the LMP primary Point of Contact

- List of the full names, emails and phone numbers of the individuals that will be authorized to submit data on behalf of the LMP

Once access has been granted, the Sustainability Manager will provide the LMP user with their credentials and the originating Service Request will be completed.

\subsection{Sustainability Manager Review of Reports}

Electronic Maintenance Reports will require review by the Sustainability Manager for the corresponding Program/Country. The report forms include the ability for the Sustainability Manager to "certify" a report as complete or request additional detail from the Local Maintenance Provider. Separate guidance is provided to Sustainability Managers detailing the review/certification requirements for various report types.

\subsubsection{Sustainability Manager “Certifies” a Report as Complete}

A Sustainability Manager may “certify” a completed Maintenance Report by selecting the "Certify” button in the Review Section within the selected report. Once an Electronic Maintenance Report has been certified, the form is no longer editable, but may be viewed within the portal by the Sustainability Manager or others with an established need-to-know. The Local Maintenance Provider will receive an email notification when the Sustainability Manager has certified the report.

\subsubsection{Sustainability Manager Requests Additional Information}

Sustainability Managers have the ability to request that the Local Maintenance Provider revise a Maintenance Report by selecting the "Un-Complete" button in the Review Section within the selected report. The Sustainability Manager has the option to include a note about the reason for un-completing the report. This note is visible to the Local Maintenance Provider along with the uncompleted report to facilitate revision. Once the report is un-completed, the Local Maintenance Provider will receive an email notification advising that they should review the Sustainability Manager's comments on the report within the SLD Portal. 


\subsection{Issue Report Form}

\subsection{Background Information (Section)}

This section is designed to capture basic information about the issue, including where the issue occurred, who is completing the form, and contact information for the Local Maintenance Provider that responded.

Country - Enter the name of the Partner Country where the site is located.

Maintenance Provider - Provide the name of the Local Maintenance Provider reporting/responding to the issue.

Completed By - This field is intended to capture the names of the individuals who worked on the reported issue. This includes the technicians who responded to the issue (onsite or remotely) and the person completing the report. The role of each person included should also be provided.

Contract - Provide the Contract, Basic Order Agreement, or other unique identifier associated with the Local Maintenance Provider's support agreement.

Phone Number - Enter the Local Maintenance Provider's business phone number.

Email - Enter the Local Maintenance Provider’s business Email address.

\subsection{Issue Information}

Issue ID - If the Local Maintenance Provider has an internal identification number used for tracking issues reported to them, they should provide that number in this field. If a site does not have an existing naming convention for tracking issues corrected by the Local Maintenance Provider, a suggested format is YYYYMMSite\#\#\# where:

- YYYYMM - four digit year and two digit month an issue was called into the LMP

- $\quad$ Site - the first four letters of the site name

- \#\#\# - a number starting with 0001 and is reset every January 1

Site - A dropdown list of sites serviced by the Local Maintenance Provider. Select the site/location, ensuring that the correct crossing type is selected (i.e. vehicle crossing (VC), rail crossing (RC), or Airport (AP)). If the issue affects multiple sites (spare parts requests) the "Country-Wide" (CW) site can be chosen. If the correct site is not represented in the dropdown list, contact the SLD Help Desk to request assistance.

Equipment Location - Enter the physical location of the affected equipment at the site. If the reported issue is with an RPM, provide the lane number (i.e. RPM1 Vehicle Lane 1, Pedestrian Lane 1, etc.)

Date Reported - This field is intended to capture the date and time that the issue was reported to the Local Maintenance Provider. The format for this date field is YYYY-MM-DD where: 
- YYYY - four digit year

- $\mathrm{MM}$ - two digit month

- $\mathrm{DD}$ - two digit day

Reported By - Provide the name of the organization that reported the issue (Customs, Port Authority, etc.) to the Local Maintenance Provider.

Priority - Identify the severity of the reported problem using the following criteria:

- Critical - Applies to issues where the system is deemed completely inoperable or diminished in function to the point that it cannot detect the target quantities and types of special nuclear material and other radioactive materials of concern.

- Major - Assigned to issues in which the system is still operational, but the ability to detect target quantities and types of special nuclear material and other radioactive materials of concern is hindered. This ranking will also have a focused impact on site operations, such as a site's ability to continue the movement of traffic efficiently because too many portals or lanes are not functioning.

- Minor - This priority is assigned to issues in which the system is operational with diminished, but tractable functionality. Unresolved issues remain within the detection system with which the LMP needs assistance, but the issues do not impact the operational capacity to detect the target quantities and types of special nuclear material and other radioactive materials of concern.

Date of Response - Enter the date/time that the Local Maintenance Provider responded to the reported issue, either by remotely troubleshooting the reported problem or by visiting the site. The format for this date field is YYYY-MM-DD where:

- YYYY - four digit year

- $\mathrm{MM}$ - two digit month

- DD - two digit day

Issue Description - Describe the issue as reported.

Diagnostic Steps - Describe the diagnostic steps taken, and the results of each step.

Help Desk Assistance Required - Check this box if a SLD Help Desk Service Request is required to resolve the issue. Upon completion of this Issue Report, the system will notify the Help Desk that a new Service Request is required.

Important: If a Service Request is already open to address this issue, leave this box unchecked and include the Service Request number in the field provided below.

Resolution - Describe the final resolution of the issue, including repaired/replaced components.

Important: If the issue was not resolved and the "Help Desk Assistance Required" checkbox is checked, the Local Maintenance Provider can use this box to capture actions that are needed to resolve the issue, if known (i.e. a part needs to be ordered). 
Date Resolved - Enter the date/time that the issue was finally resolved. The format for this date field is YYYY-MM-DD where:

- $\quad$ YYYY - four digit year

- $\mathrm{MM}-$ two digit month

- $\quad$ DD - two digit day

Important: If the issue was not resolved and the "Help Desk Assistance Required” checkbox is checked, this field must be left blank.

Help Desk Involved? - This is a checkbox used to identify whether the issue is related to an existing SLD Help Desk Service Request.

Service Request \# - If the issue is related to an existing SLD Help Desk Service Request, enter the Service Request number. If there is no existing Service Request, leave this field blank.

Issue Category - Select the Issue Category that applies to this issue. A detailed list of Issue Categories/Subcategories is included in Appendix A of this document.

Issue Subcategory1 - Select the Issue Subcategory that applies to this issue. The contents of this list are dependent upon the selection of the Issue Category above. A detailed list of Issue Categories/Subcategories is included in Appendix A of this document.

Issue Subcategory2 - Select the Issue Subcategory that applies to this issue. The contents of this list are dependent upon the selection of the Issue Subcategory1 above. A detailed list of Issue Categories/Subcategories is included in Appendix A of this document.

Issue Subcategory3 - Select the Issue Subcategory that applies to this issue. The contents of this list are dependent upon the selection of the Issue Subcategory2 above. A detailed list of Issue Categories/Subcategories is included in Appendix A of this document.

Issue Subcategory4 - Select the Issue Subcategory that applies to this issue. The contents of this list are dependent upon the selection of the Issue Subcategory3 above. A detailed list of Issue Categories/Subcategories is included in Appendix A of this document.

Attachments - The attachments field allows the Local Maintenance Provider to attach additional documentation related to the reported Issue.

Important: Attached files cannot be used in place of completing fields in the report forms.

Important: File attachments in the Electronic Maintenance Reports do not fulfill the Local Maintenance Provider requirement to upload “daily files” or other archiving. Local Maintenance Providers must continue to submit these files as required by their contracts via the ORNL secure upload site. 


\subsection{Parts and Materials Used}

This section is intended to capture whether parts were used to resolve the issue, what parts were used, and whether the Local Maintenance Provider requires replenishment for the consumed parts.

Spare Parts Used? - This checkbox should be checked if parts were used from the Local Maintenance Provider's spare parts inventory.

Spare Parts - The Local Maintenance Provider will use the fields in this table to identify parts used from their spare parts inventory. Additional rows can be added or removed as needed.

Subsequent sections describe each field in the table.

Part\#/Description - Provide the part number or a part description in this field.

QTY - List the quantity of this part that was used to resolve this issue.

Location Deployed - Briefly describe the location where the replacement parts were deployed.

Date/Time - Date/time the part was used. The format for this date field is YYYY-MMDD where:

- $\quad$ YYYY - four digit year

- $\quad \mathrm{MM}$ - two digit month

- DD - two digit day

Replacement Needed - The Local Maintenance Provider can check this box to indicate that this part will need to be replenished in their spare parts inventory.

Important: Checking the "Replacement Needed" box will not automatically result in a shipment of new spare parts. Local Maintenance Providers will still need to submit a formal request for spare parts following the Sustainability Manager's guidance.

Stock Remaining - The Local Maintenance Provider reports how many of the identified part is remaining in their spare parts inventory.

Other Parts and Materials Used? - This checkbox should be checked if parts or other materials that were not part of the Local Maintenance Provider’s spare parts inventory.

Other Parts and Materials - The Local Maintenance Provider will use the fields in this table to identify parts that were not part of the spare parts inventory. Additional rows can be added or removed as needed. Subsequent sections describe each field in the table.

Part\#/Description - Provide the part number or a part description in this field.

QTY - List the quantity of this part that was used to resolve this issue. 
Location Deployed - Briefly describe the location where the replacement parts were deployed.

Date/Time - Date/time the part was used. The format for this date field is YYYY-MM-DD where:

- $\quad$ YYY - four digit year

- $\mathrm{MM}$ - two digit month

- $\mathrm{DD}$ - two digit day

Replacement Needed - The Local Maintenance Provider can check this box to indicate that they would like to have this part replenished as a new item in their spare parts inventory.

Important: Checking the "Replacement Needed" box will not automatically result in a shipment of new spare parts. Local Maintenance Providers will still need to submit a formal request for spare parts following the Sustainability Manager's guidance.

Stock Remaining - This field does not need to be completed for parts that are not included in the Local Maintenance Provider's spare parts inventory.

\subsection{Review Section}

The Review Section displays all of the information entered on a single read-only form that can be easily reviewed and printed prior to completion.

Important: Once a Maintenance Report Form is marked complete, it will no longer appear in the Local Maintenance Provider's list of in-progress reports.

Sections on the review screen can be expanded or collapsed using the "+” and "-“ buttons or the "Expand All"/"Collapse All" buttons at the top of the screen.

If changes need to be made to one of the previous sections, the user can navigate to the related section using the menu on the left side of the screen to return to the desired section or by selecting the "previous" button to be returned to the "Parts and Materials Used" section. 


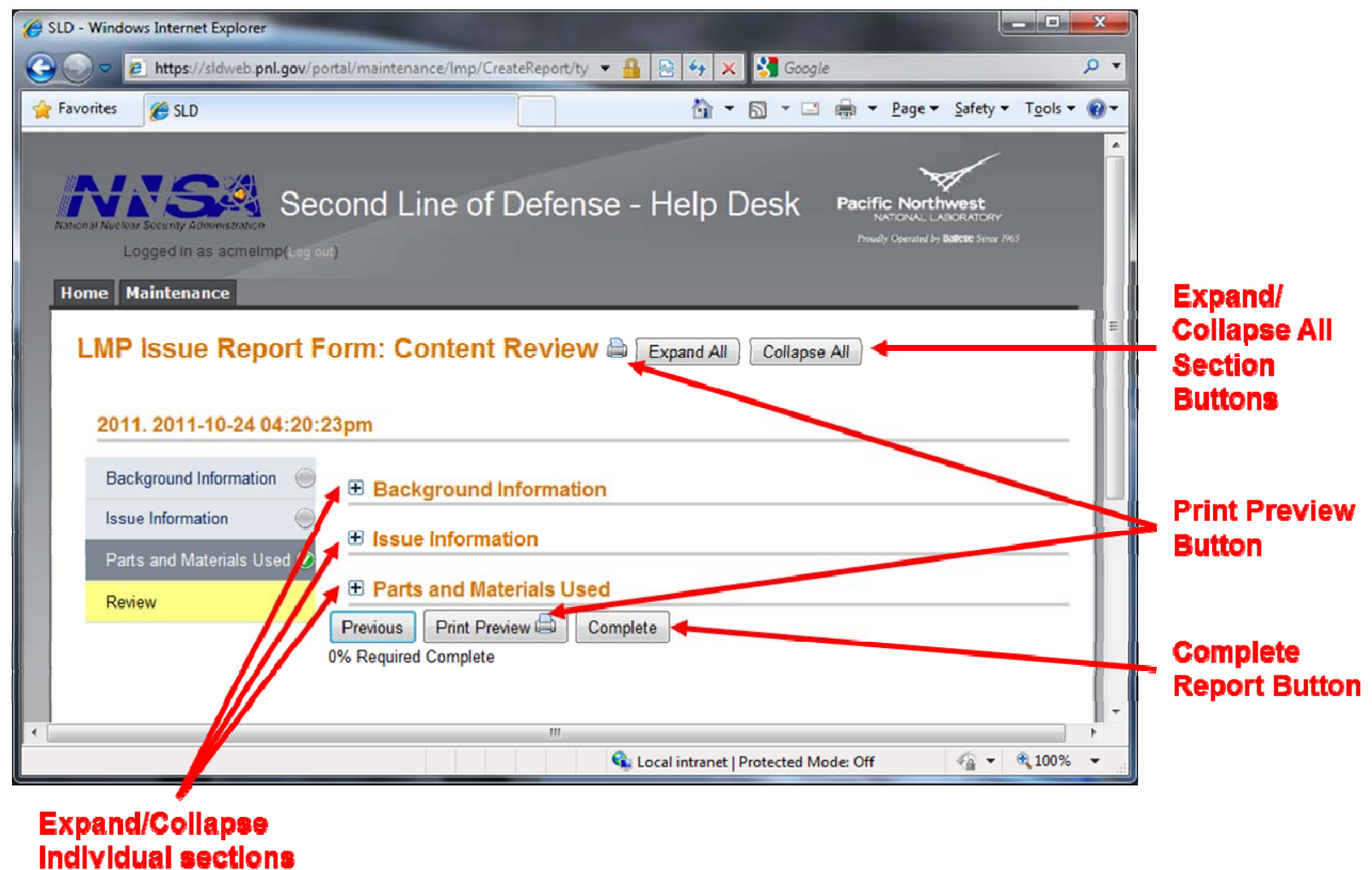

Figure 6. Content Review Screen Features

\subsubsection{Printing/Saving a copy of the report prior to Completion}

To print or save a copy of the report prior to marking it complete, the user can click one of two "Print Preview" buttons on the screen, as indicated in the Figure below. This will open a new window with a copy of the report that is formatted for printing.

\subsubsection{Print the Report}

To print the page, select "Print..." from the "File" menu within the browser or click the printer icon in the toolbar. In most browsers, the report can also be printed by pressing "Ctrl-P” on the keyboard.

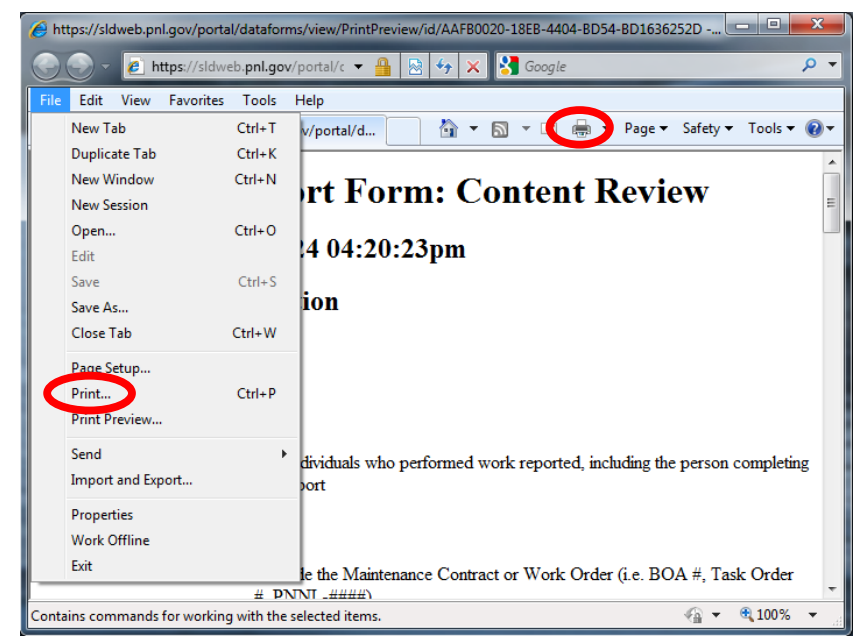




\section{Figure 7. Printing a Report before Completion}

\subsubsection{Save the Report}

To save an electronic copy of the report, select "Save As..." from the "File” menu within the browser.

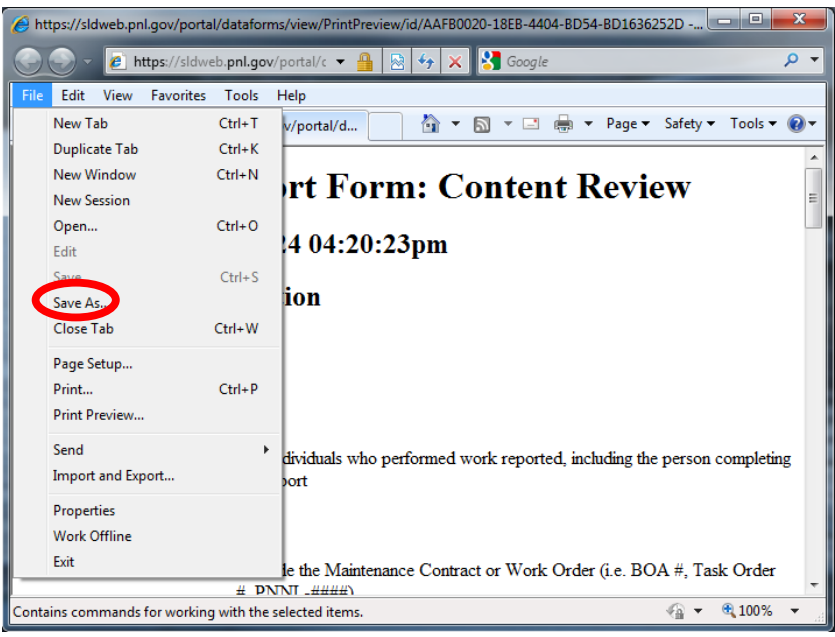

Figure 8. Saving a Report before Completion

Enter the desired filename, select the preferred file type, and click "Save".

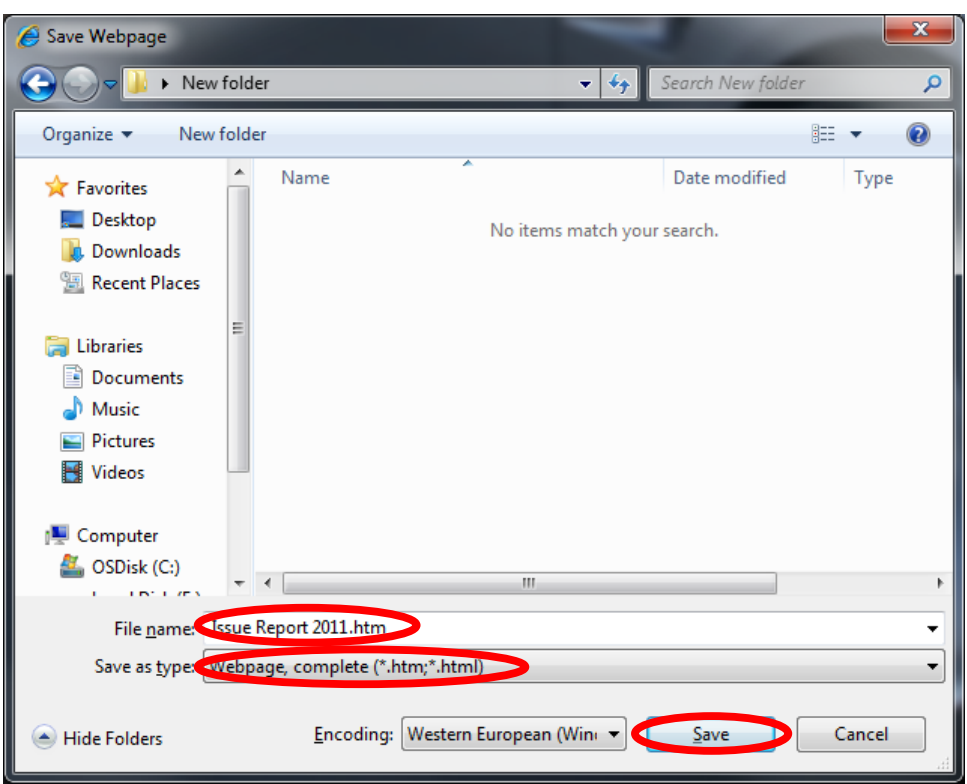

Figure 9. Naming the File 


\subsubsection{Completing the Report}

Once the Local Maintenance Provider has reviewed their report, they can select the "Complete" button at the bottom of the Content Review page to submit their report to the Sustainability Manager for review. The following warning box will appear:

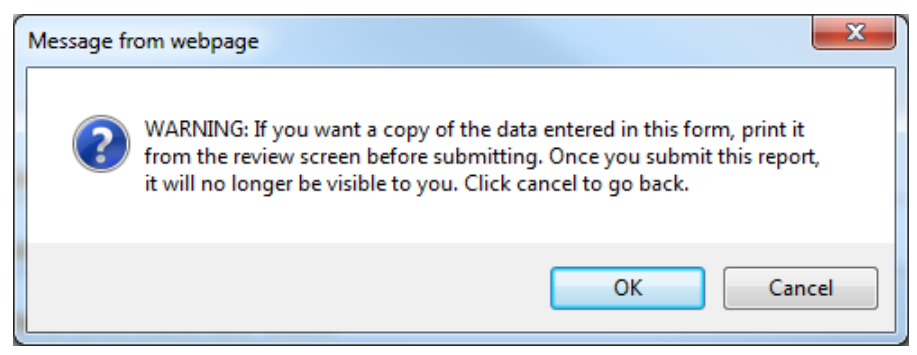

Figure 10. Report Completion Warning Dialogue

Press "OK” to mark the report complete, or press "Cancel” to return to the report form without completing the report.

\subsection{Sustainability Manager Content Review}

After the Maintenance Report Form has been marked complete by the Local Maintenance Provider, the Sustainability Manager will review the report. The Sustainability Manager will either "Certify" the report as received or "Un-Complete" the report.

If a Sustainability Manager marks a Maintenance Report "Un-Complete", there is an option to include a note about the reason for un-completing the report. This note is visible to the Local Maintenance Provider along with the uncompleted report to facilitate revision. The un-completed report appears in the Local Maintenance Provider's list of in-progress reports. The Local Maintenance Provider can then edit the form to provide the information requested by the Sustainability Manager and then "Complete" the report again. 


\subsection{Monthly Report}

\subsection{Background Information}

This section is designed to capture basic information about the Monthly Maintenance Report, including who performed the work, contact information for the Local Maintenance Provider, and the start date/end date for the reporting period.

Country - Enter the name of the Partner Country where the site is located.

Maintenance Provider - Provide the name of the Local Maintenance Provider.

Completed By - This field is intended to capture the names of the individuals who completed preventative maintenance work during the reporting period. This includes the technicians that visited the site and the person completing the report. The role of each person included should also be provided.

Contract - Provide the Contract, Basic Order Agreement, or other unique identifier associated with the Local Maintenance Provider’s support agreement.

Phone Number - Enter the Local Maintenance Provider’s business phone number.

Email - Enter the Local Maintenance Provider’s business Email address.

Report Start Date - Provide the start date for the reporting period. The format for this date field is YYYY-MM-DD where:

- $\quad$ YYYY - four digit year

- $\mathrm{MM}-$ two digit month

- $\mathrm{DD}$ - two digit day

Report End Date - Provide the end date for the reporting period. The format for this date field is YYYY-MM-DD where:

- YYYY - four digit year

- $\mathrm{MM}$ - two digit month

- $\mathrm{DD}$ - two digit day

\subsection{Preventative Maintenance}

Preventative Maintenance information is captured at the site-level within the report and the form allows the user to add multiple sites to a single report. By default the Site Specific Information sub-sections are collapsed. The "+” button next to "Site Specific Information" heading can be clicked to expand the subsection, revealing the fields described in this section. Additional sites can be added to the report and may be removed if a mistake is made. 


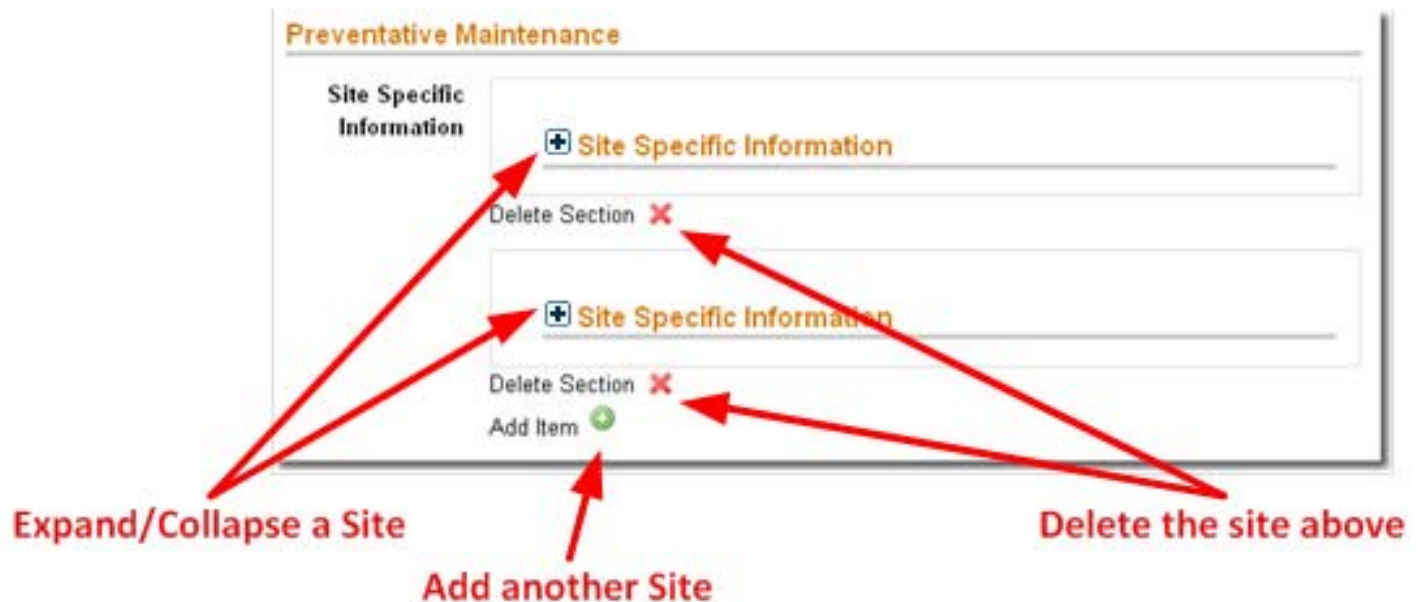

Figure 11. Site Specific Information Options.

Site - A dropdown list of sites serviced by the Local Maintenance Provider. Select the site/location, ensuring that the correct crossing type is selected (i.e. vehicle crossing (VC), rail crossing (RC), or Airport (AP)). If the issue affects multiple sites (spare parts requests) the "Country-Wide" (CW) site can be chosen. If the correct site is not represented in the dropdown list, contact the SLD Help Desk to request assistance.

Date of Visit(s) - This field captures the dates that the site was visited for preventative maintenance. Additional dates can be added if multiple visits were made to complete all preventative maintenance activities. . The format for this date field is YYYY-MM-DD where:

- $\quad$ YYYY - four digit year

- $\mathrm{MM}$ - two digit month

- $\mathrm{DD}$ - two digit day

Preventative Maintenance Completed - This checkbox provides a simple mechanism for the Local Maintenance Provider to indicate that they completed all Preventative Maintenance, including any checklists, as required by the maintenance contract. Local Maintenance Providers should attach any completed checklists using the attachments option described below.

Equipment Counts - This section requires the Local Maintenance Provider to identify equipment deployed at the site and the status of the equipment upon their arrival to perform schedule maintenance, as well as at departure. The first row of the table is always present, albeit initially empty. For each additional system, the user can add a row using the "Add Item" button below the table

System - The user must select from a pre-defined list of systems for which counts are required. 
Total - The total number of specified system deployed at the site.

Broken - The number of the identified systems that were found to be broken during the visit.

Repaired - The number of the previously identified "broken” systems that were repaired prior to departure.

Observations - This field captures site-specific observations made during the preventative maintenance visit(s).

Attachments - The attachments field allows the Local Maintenance Provider to attach additional documentation related to the preventative maintenance visit, such as Contract Appendices Checklists, photos, etc..

Important: Attached files cannot be used in place of completing fields in the report forms.

Important: File attachments in the Electronic Maintenance Reports do not fulfill the Local Maintenance Provider requirement to upload “daily files” or other archiving. Local Maintenance Providers must continue to submit these files as required by their contracts via the ORNL secure upload site.

Consumable Parts - The Local Maintenance Provider will use the fields in this table to identify consumable parts, such as desiccant, that were used during preventative maintenance visit. Equipment parts that are replaced to repair/return a system to operation should be documented in a separate Issue Report form. Additional rows can be added or removed as needed. Subsequent sections describe each field in the table.

Part\#/Description - Provide the part number or a part description in this field.

QTY - List the quantity of part(s) that were consumed.

Location Deployed - Briefly describe the location where the consumable parts were deployed (i.e. RPM enclosures lanes 1-4).

Date/Time - Date/time the consumable part was used/consumed. The format for this date field is YYYY-MM-DD where:

- $\quad$ YYYY - four digit year

- $\mathrm{MM}$ - two digit month

- $\mathrm{DD}$ - two digit day

Replacement Needed - The Local Maintenance Provider can check this box to indicate that they would like to have this part replenished as a new item in their spare parts inventory. 
Important: Checking the "Replacement Needed" box will not automatically result in a shipment of new spare parts. Local Maintenance Providers will still need to submit a formal request for spare parts following the Sustainability Manager’s guidance.

Stock Remaining - The Local Maintenance Provider reports how many of the identified part is remaining in their spare parts inventory.

\subsection{Related Issues \& Comments}

Related Issues - This field allows the Local Maintenance Provider to add a reference to one or more Issue Reports into the Monthly Report.

Comments - Additional Vendor Report Comments that do not apply at the site-level.

\subsection{Review Section}

The Content Review Section displays all of the information entered on a single read-only form that can be easily reviewed and printed prior to completion.

Important: Once a Maintenance Report Form is marked complete, it will no longer appear in the Local Maintenance Provider's list of in-progress reports.

Sections on the review screen can be expanded or collapsed using the "+” and "_" buttons or the "Expand All"/"Collapse All” buttons at the top of the screen.

If changes need to be made to one of the previous sections, the user can navigate to the related section using the menu on the left side of the screen to return to the desired section or by selecting the "previous" button to be returned to the "Related Issues \& Comments" section. 


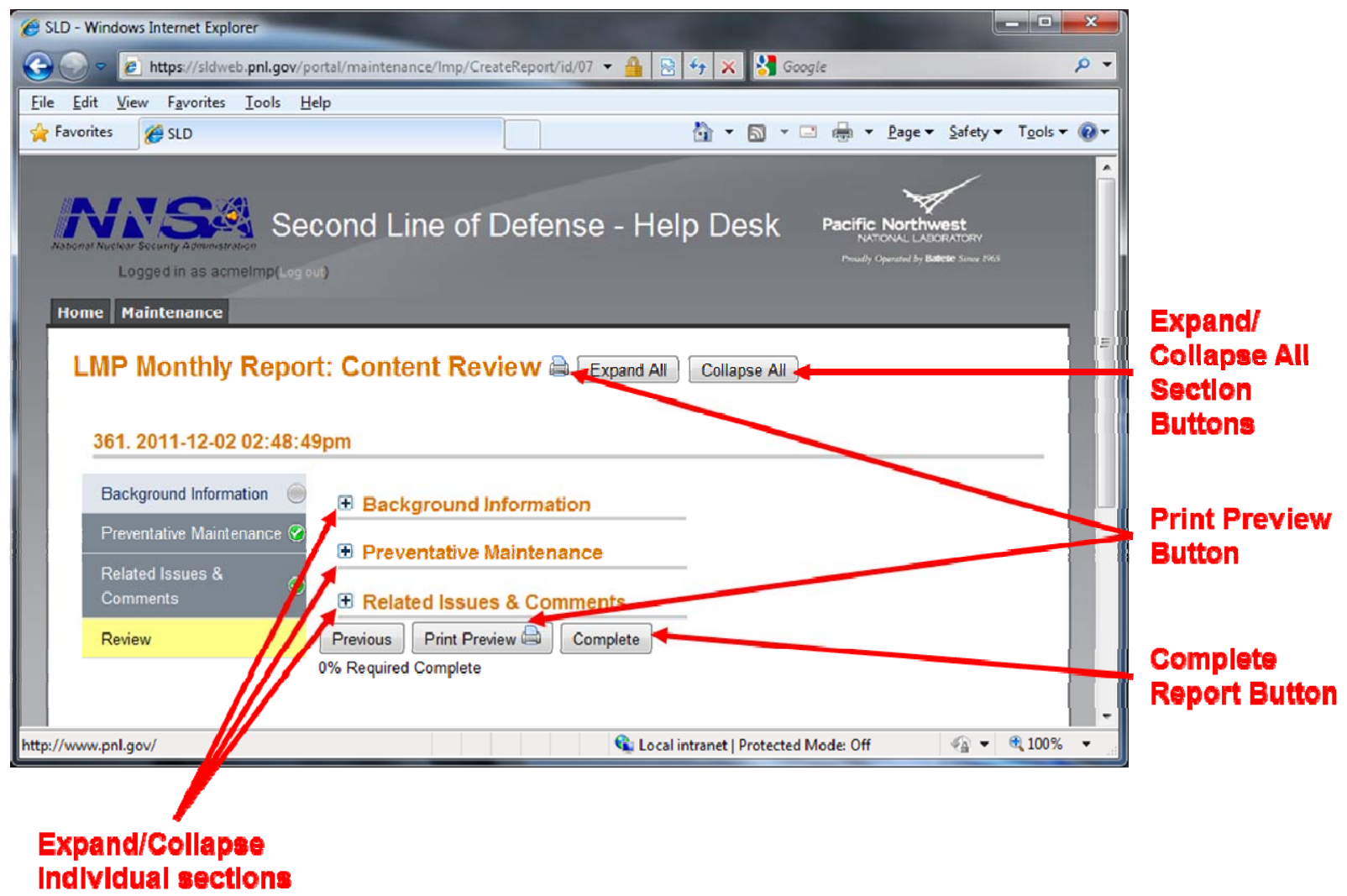

Figure 12. Content Review Screen Features

\subsubsection{Printing/Saving a copy of the report prior to Completion}

To print or save a copy of the report prior to marking it complete, the user can click one of two "Print Preview" buttons on the screen, as indicated in the Figure below. This will open a new window with a copy of the report that is formatted for printing.

\subsubsection{Print the Report}

To print the page, select "Print..." from the "File" menu within the browser or click the printer icon in the toolbar. In most browsers, the report can also be printed by pressing "Ctrl-P" on the keyboard. 


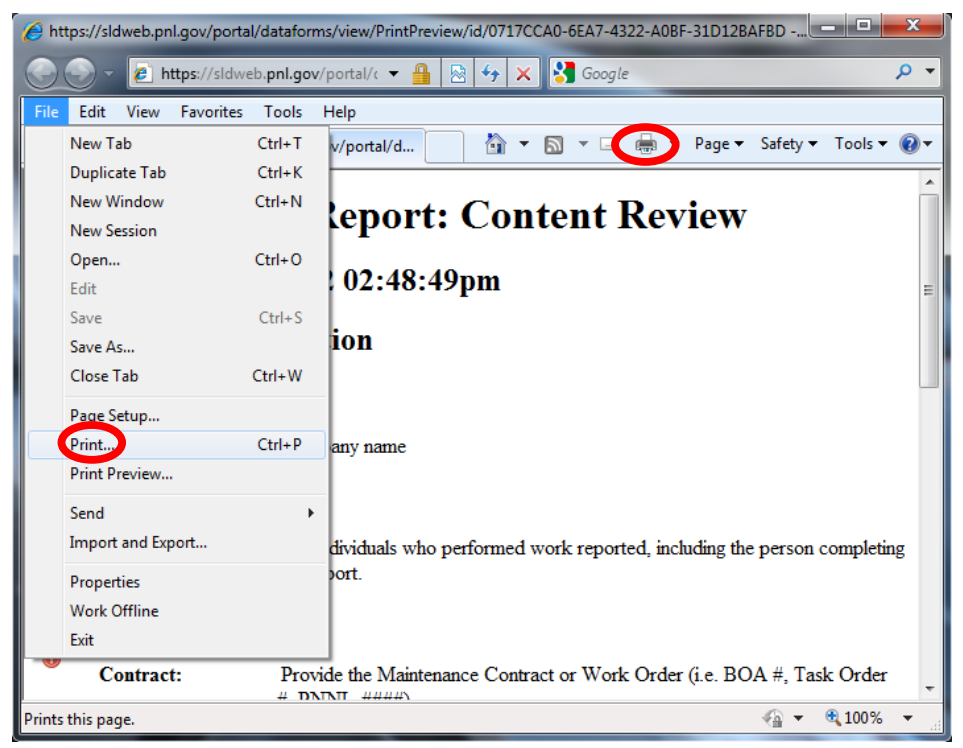

Figure 13. Printing a Report before Completion

\subsubsection{Save the Report}

To save an electronic copy of the report, select "Save As...” from the "File” menu within the browser.

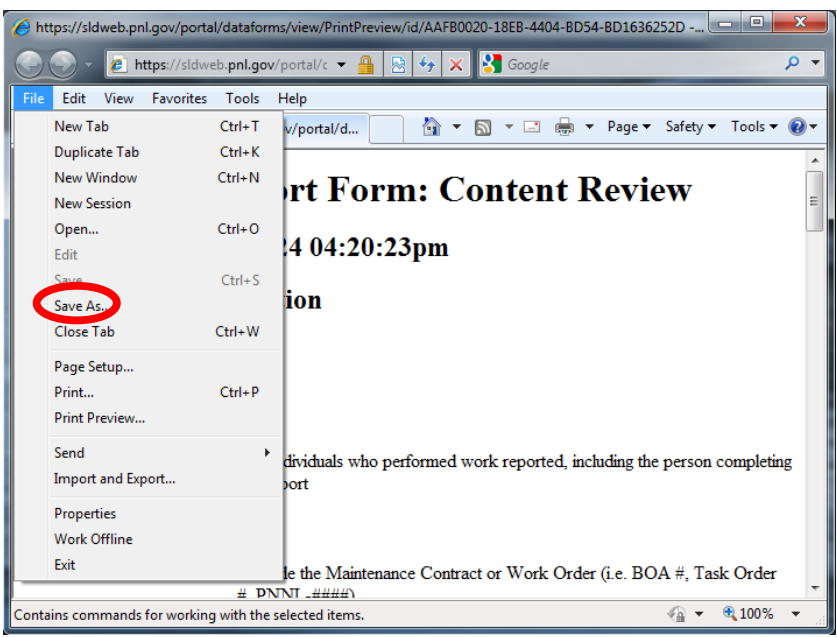

Figure 14. Saving a Report before Completion

Enter the desired filename, select the preferred file type, and click "Save". 


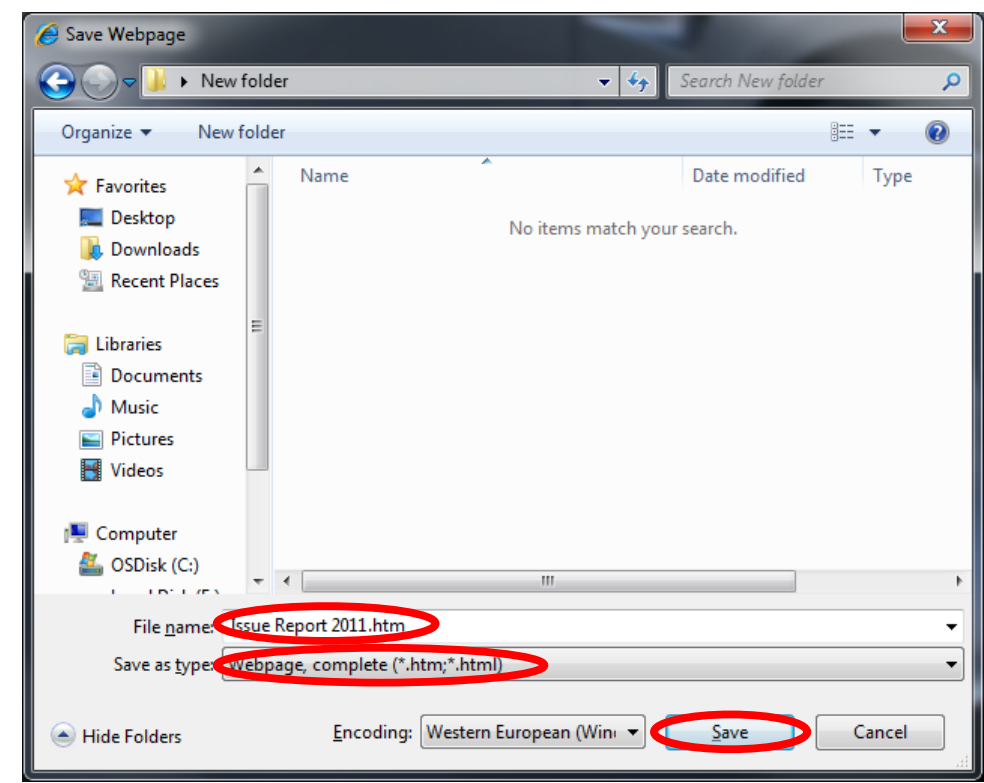

Figure 15. Naming the File

\subsubsection{Completing the Report}

Once the Local Maintenance Provider has reviewed their report, they can select the "Complete" button at the bottom of the Content Review page to submit their report to the Sustainability Manager for review. The following warning box will appear:

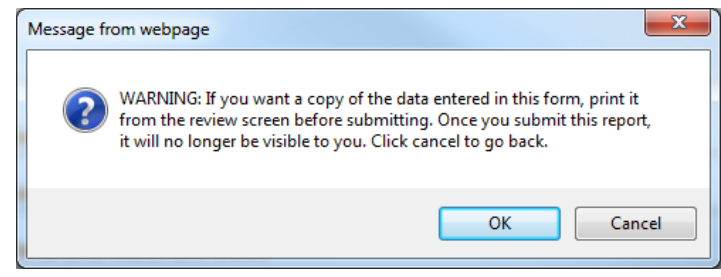

Figure 16. Report Completion Warning Dialogue

Press "OK” to mark the report complete, or press "Cancel” to return to the report form without completing the report.

\subsection{Sustainability Manager Content Review}

After the Maintenance Report Form has been marked complete by the Local Maintenance Provider, the Sustainability Manager will review the report. The Sustainability Manager will either "Certify" the report as received or "Un-Complete" the report.

If a Sustainability Manager marks a Maintenance Report "Un-Complete", there is an option to include a note about the reason for un-completing the report. This note is visible to the Local Maintenance Provider along with the uncompleted report to facilitate revision. The un-completed report appears in the Local Maintenance Provider's list of in-progress reports. The Local Maintenance Provider can then edit the form to provide the information requested by the Sustainability Manager and then "Complete" the report again. 


\section{Appendix A. Issue Resolution Categories}

(November 30, 2010)

Issue and Service Request resolutions are sorted in to eight major categories. Within each category can be multiple sub-categories

1. Radiation Detection

a. Radiation Portal Monitor (RPM)

i. Gamma Detector

ii. Neutron Detector

iii. Occupancy Sensor

iv. Camera

v. Electronic Controls

vi. Power Supply

1. Utility Cabinet Enclosure

a. Distribution Box

b. Conditioner

2. Door Locks

3. Circuit Breaker

4. Surge Protection

vii. Battery Backup

viii. Detector Enclosure

b. Spectroscopic Portal Monitor (SPM)

i. Gamma Detector

ii. Neutron Detector

iii. Occupancy Sensor

iv. Camera

v. Internal Computer

vi. Power System

1. Utility Cabinet Enclosure

a. Distribution Box

b. Conditioner

2. Door Locks

3. Circuit Breaker

4. Surge Protector

vii. Detector Enclosure

viii. Software

c. Mobile Radiation Detection and Identification System (MRDIS)

i. Gamma Detector

ii. Neutron Detector

iii. Detector Enclosure

iv. Electronic Controls

v. Software

vi. Power System

vii. Hydraulics, steering, air-suspension systems

viii. Metal Frame 
d. Straddle Carrier

i. Gamma Detector

ii. Neutron Detector

iii. Electronic Controls

iv. Software

v. Power System

e. Mobile Detection System (MDS; van-mounted)

i. Gamma Detector

ii. Neutron Detector

iii. Occupancy Sensor

iv. Electronic Controls

v. Software

vi. MDS Vehicle

f. Handheld Detectors

i. Personal Radiation Detector (PRD)

ii. Radioactive Isotope Identification Device (RIID)

iii. High Resolution (RIID) - Ortec (HPGe)

iv. Survey Meter

v. Batteries

2. Central Alarm Station (System)

a. Server

i. Hardware

ii. Un-interrupted Power Supply

iii. Data Management

iv. User Access

b. Software

c. Operator Workstations

i. Un-interrupted Power Supply

ii. Hardware

iii. Software

iv. Data Management

1. User Access

d. Reader Board

3. Network/Communications
a. Phone System

b. LAN Hardware

i. Wireless

ii. Router

iii. Switch

iv. Media Converter

c. Cabling

d. Service Provider

4. Optical Character Recognition (OCR)

a. OCR Lane Computer

i. Un-interrupted Power Supply

ii. Hardware

iii. Software

iv. Data Management 


\section{User Access}

b. OCR System

i. Cameras

ii. Lights

iii. Ground Loops

c. OCR Server

i. Un-interrupted Power Supply

ii. Software

iii. Hard Drive

iv. Memory

v. Data Management

1. User Access

5. Administrative Tasks
a. Contracting
b. Shipping
c. Accounts Payable
d. Manuals
e. Media Requests

6. Operations

a. Training

i. Operator

ii. Maintenance

b. Parts

i. Replenish Spares

1. Desiccant

ii. Replacement

iii. Initial Equipment Order

c. Traffic Control

d. Site Infrastructure, Construction, or Modifications

e. Auxiliary Power

i. Generator

7. Software Administration
a. VPN Administration
b. Username/Password Administration
c. Anti-Virus Administration
d. Patch Administration
e. Operating System Administration

8. Other 


\section{Appendix B: Category and Subcategory Definitions}

(November 30, 2010)

Below are category and subcategory descriptions. If the category or subcategory is self explanatory, then no further description is provided.

1. Radiation Detection - Radiation detection equipment commonly deployed in Partner Countries such as RPM, MRDIS and handhelds. This equipment detects radioactive materials.

a. Radiation Portal Monitors (RPM) - radiation detection equipment typically consisting of two pillars with radiation (gamma and neutron) detector panel(s) on each side, which are remotely monitored from a display panel to screen traffic. The system includes:

i. Gamma detectors - detector is scintillating plastic (PVT) with photomultiplier tube

ii. Neutron detectors - detectors are plastic covered tubes containing He-3 gas

iii. Occupancy sensors - ultrasonic or infrared technologies used to detect presence of traffic (people, vehicles or containers).

iv. Electronics - detect electrical pulse from the photomultiplier tube and converts it to a "count"

v. Battery Backup

vi. Detector Enclosure

vii. Power Supply

1. Utility cabinet enclosure

a. Distribution box

b. Conditioner

2. Door locks

3. Circuit breaker

4. Surge protector

viii. Camera(s) - used to enable identification of the traffic (vehicle or person) generating an alarm.

b. Spectroscopic Portal Monitors (SPM) - radiation detection equipment typically consisting of two pillars with radiation (gamma and neutron) detector panel(s) on each side, which are remotely monitored from a display panel to screen traffic. The system includes:

i. Gamma detectors - detectors are materials that enable high resolution spectral analysis such as Nal crystals.

ii. Neutron detectors - detectors are plastic covered tubes containing He-3 gas

iii. Occupancy sensors - ultrasonic or infrared technologies used to detect presence of traffic (people, vehicles or containers).

iv. Camera- used to enable identification of the traffic (vehicle or person) generating an alarm

v. Internal computer - detect signal and processes it into spectra

vi. Battery Backup

vii. Detector Enclosure

viii. Software

ix. Power Supply

1. Utility cabinet enclosure

a. Distribution box

b. Conditioner 
2. Door locks

3. Circuit breaker

4. Surge protector

c. Straddle Carrier - radiation detection equipment attached to a straddle carrier. The straddle carrier is used to stack or move shipping containers at port terminals and intermodal yard (See figure 1 for example)

i. Gamma detectors

ii. Neutron detectors

iii. Detector Enclosure

iv. Electronics controls

v. Software

vi. Power Supply

d. Mobile Radiation Detection and Identification System (MRDIS) - is a self contained mobile unit that is not a vehicle (See figure 2 for example) which includes:

i. Gamma detectors

ii. Neutron detectors

iii. Detector Enclosure

iv. Electronics controls

v. Software

vi. Power Supply

vii. Hydraulics, steering, air-suspension systems

viii. Metal frame

e. Mobile Detection System (van-mounted) - a vehicle, typically a van, retrofitted with radiation detection equipment and alarm system.

i. Gamma detectors

ii. Neutron detectors

iii. Electronics controls

iv. Software

v. MDS vehicle

f. Handheld Detectors - Portable, light weight radiation detectors (See figure 3 for examples).

i. Personal Radiation Detector (PRD) - is wearable gamma and/or neutron radiation detector, approximately the size of a pager.

ii. Radiation Isotope Identification Device (RIID) - Handheld gamma (Sodium lodine-Nal) and neutron (Helium-3 tube) detector typically used to locate and identify radioactive material.

iii. High Resolution Radiation Isotope Identification Device (RIID) - Handheld gamma detector (typically high purity germanium- HPGe) with high resolution spectra for accurate and reliable radioactive isotope identification.

iv. Survey Meter - radiation detection equipment which is more sensitive in gross radiation counts than a PRD or RIID. It is used for searching.

$v$. Batteries - power source inside the handheld detectors.

2. Central Alarm System - Equipment and software which provide information that allow an operator to monitor system status, analyze alarm information, document alarm disposition and archive pertinent data.

a. Server - one or series of computers that link other computers or electronic devices together

i. Hardware

ii. Un-interrupted power supply 
iii. Data management

iv. User access

b. Software

c. Operator desktop computer

i. Hardware

ii. software

iii. Un-interrupted power supply

iv. Data management

1. User access

d. Reader Board

3. Network / communication-group of computers and devices interconnected by communications channels that facilitate communications among users and allows users to share resources.

a. LAN (Local Area Network) Hardware

i. Phone system

ii. LAN Hardwar

1. Router - a device that forwards and filters OSI layer 2 datagrams (chunk of data communication) between ports (connected cables) based on the MAC addresses in the packets

2. Switch - an internetworking device that forwards packets between networks by processing information found in the datagram or packet

3. Wireless

4. Media converter

iii. Cabling

iv. Service provider

4. Optical Character Recognition - The system recognizes and captures the shape of characters on for example shipping containers and translates the characters into a form that a computer can manipulate.

a. OCR Lane Computer

i. Hardware

ii. Software

iii. Un-interrupted power supply

iv. Data management

1. User access

b. OCR System

i. Camera

ii. Lights

iii. Ground loops

c. OCR server

i. Software

ii. Hard drive

iii. Un-interrupted power supply

iv. Memory

v. Data management

1. User access 
5. Administrative - business aspects
a. Contracting
b. shipping
c. Accounts payable
d. Manuals
e. Media request

6. Operations - all general activities and equipment used to allow a site to function in continuous good working
a. Training
i. Operators training - examples are system administration training, or system operation training.
ii. Maintenance training

b. Parts

i. Replenishment of stock - the site has stock but it is running low so we send more to increase the stock

ii. Desiccant

iii. Replacement - the site is out of something or does not have a back-up so we need to send them a replacement.

\section{Desiccant}

iv. Initial equipment - initial stocking of spare parts

c. Traffic control-modification or replacement of traffic controlling equipment such as traffic controlling gates/arms or bollards

d. Site Infrastructure Construction or Modification - examples are pavement, speed bumper, painting, and signage

e. Auxiliary Power-supplemental or additional power sources beyond those integrated into the radiation detection system

i. Generator

7. Software Administration -

a. VPN administration - Providing VPN access to a vendor or other entity with a need to a Partner Countries' system.

b. Username/Password administration - Providing a Partner Country with passwords or usernames

c. Anti-virus administration - procurement, installation or maintenance of anti-virus software or malware software

d. Patch Administration - administration of software upgrades or patches

e. Operating System Administration - Actions taken to administer the computing applications run on the machine which acts as an interface between hardware and user. The operating system is responsible for managing and coordinating activities and sharing computer resources that acts as a host for. 


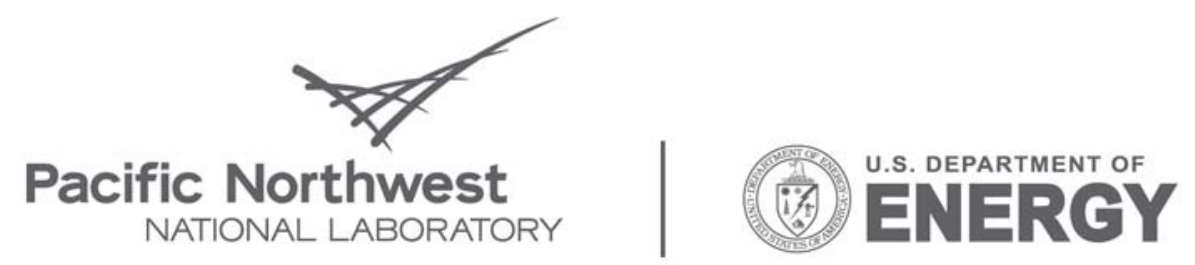

Proudly Operated by Battelle Since 1965

902 Battelle Boulevard

P.O. Box 999

Richland, WA 99352

1-888-375-PNNL (7665)

www.pnl.gov 